\title{
Evolving particle size is the key to improved volcanic forcings
}

Graham Mann ${ }^{1,2}$, S. Dhomse ${ }^{2}$, T. Deshler ${ }^{3}$, C. Timmreck ${ }^{4}$, A. Schmidt², R. Neely ${ }^{1,2}$ and L. Thomason ${ }^{5}$

\begin{abstract}
Accurate volcanic forcing estimates are pivotal for robust simulation of global mean surface temperature trends. Interactive stratospheric aerosol microphysics models calculate aerosol-radiation interactions and sedimentation rates consistently with a globally varying particle size, which improves the fidelity of simulated climate impacts.
\end{abstract}

Major volcanic eruptions inject sulfur dioxide $\left(\mathrm{SO}_{2}\right)$ into the stratosphere, abruptly increasing the stratospheric aerosol burden, with the decay back to pre-eruption conditions taking several years (Fig. 1). The aerosols have long-lasting global impacts on climate (e.g. Robock 2000), principally surface cooling through increased scattering of solar radiation, which is partially offset via increased absorption of terrestrial radiation, heating the stratosphere. Accurately characterizing these shortwave and longwave radiative effects is critical for robust attribution of anthropogenic climate change.

The injected $\mathrm{SO}_{2}$ oxidizes to sulfuric acid vapor causing new particle formation and condensation onto existing particles, which, together with ongoing coagulation, grows aerosol particles to larger sizes than in quiescent conditions (e.g. Deshler 2008). The size shift increases the solar scattering efficiency and controls the stratospheric heating since only coarser particles absorb solar near-infrared and terrestrial longwave radiation (Lacis et al. 1992). Larger particles also fall faster, which causes a vertical gradient in the particle size distribution and limits the impacts from very large eruptions (e.g. Pinto et al. 1989).

In the case of major tropical eruptions, such as the 1991 Pinatubo eruption, the stratospheric heating enhances the equator-to-pole temperature gradient in the lower stratosphere causing a stronger polar vortex and inducing chemical and dynamical changes with complex associated short-term climate responses (e.g. Graf et al. 1993). For example, mid-latitude North America and Eurasian winters were warmer following major $20^{\text {th }}$ century eruptions (Robock and Mao 1992).

Microphysical processes therefore play a key role in determining volcanic impacts on climate, and Timmreck (2012) identified the need for model intercomparisons and greater evaluation against observations to better constrain radiative forcings.

\section{Prescribed volcanic forcings may cause biases}

All but one of the climate models that performed CMIP5 historical simulations used prescribed volcanic radiative forcing datasets based on observationally-derived reconstructions of aerosol optical depth following major eruptions (e.g. Sato et al. 1993). Many also calculate radiative effects assuming a globally uniform particle size distribution, which may have overestimated volcanic cooling in the simulations (Canty et al. 2013). Indeed, deficiencies in prescribed volcanic forcings have been identified as a likely contributor to discrepancies between climate model and observed global mean surface temperature (GMST) trends (Marotzke and Forster 2015).
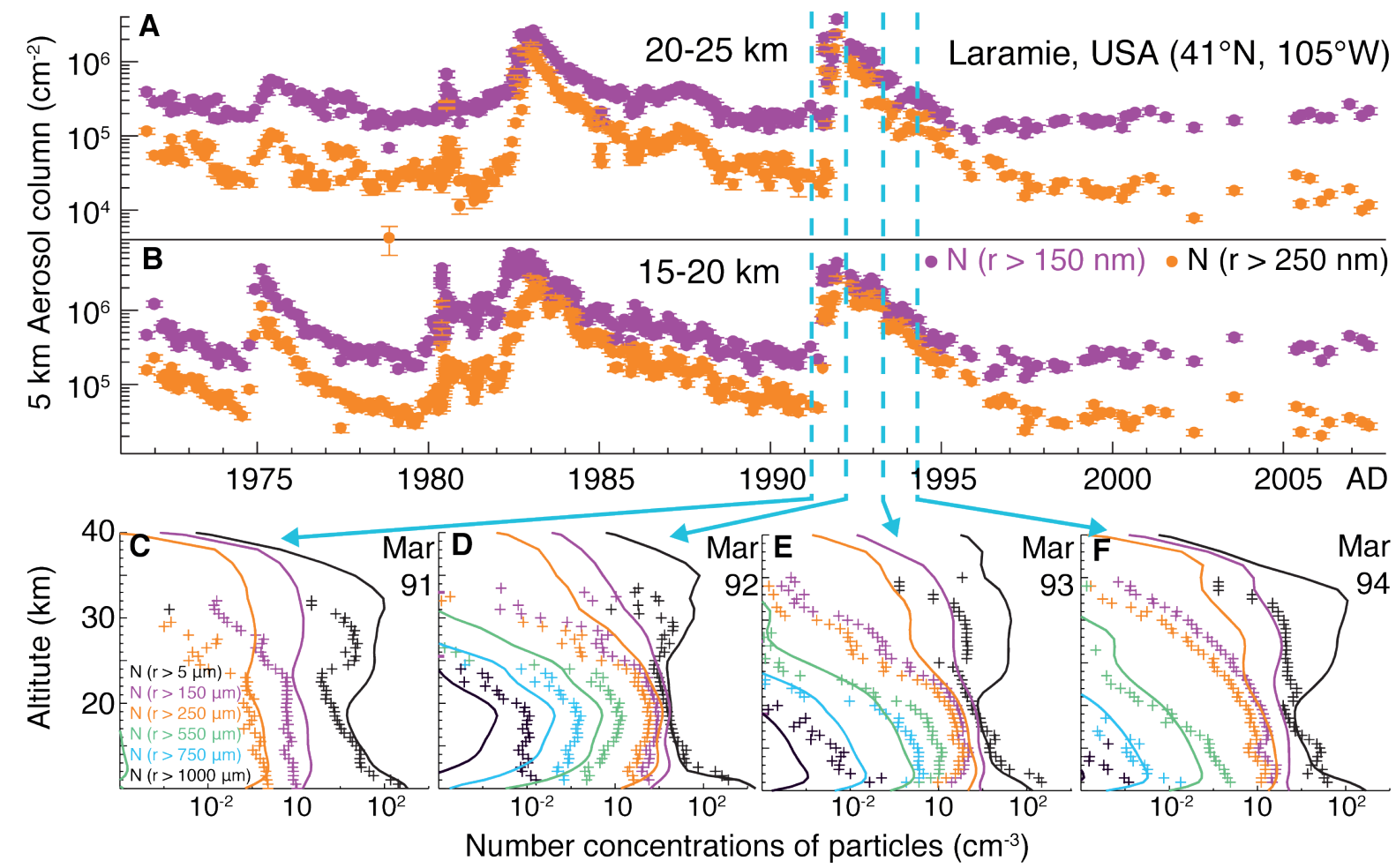

Figure 1: The 30+ year record of column-integrated size-resolved stratospheric aerosol particle concentrations at altitudes of (A) $20-25 \mathrm{~km}$ and (B) $15-20 \mathrm{~km}$ from balloon soundings at Laramie, USA (from Deshler 2008). (C-F) Example evaluation of the UM-UKCA model (Dhomse et al. 2014) simulated particle size distribution (dashed lines) before (C) and after (D, E, F) the June 1991 Pinatubo eruption compared to measured particle concentrations (crosses) larger than different size thresholds (colors) and total particle concentrations larger than $5 \mathrm{~nm}$ radius (black). 


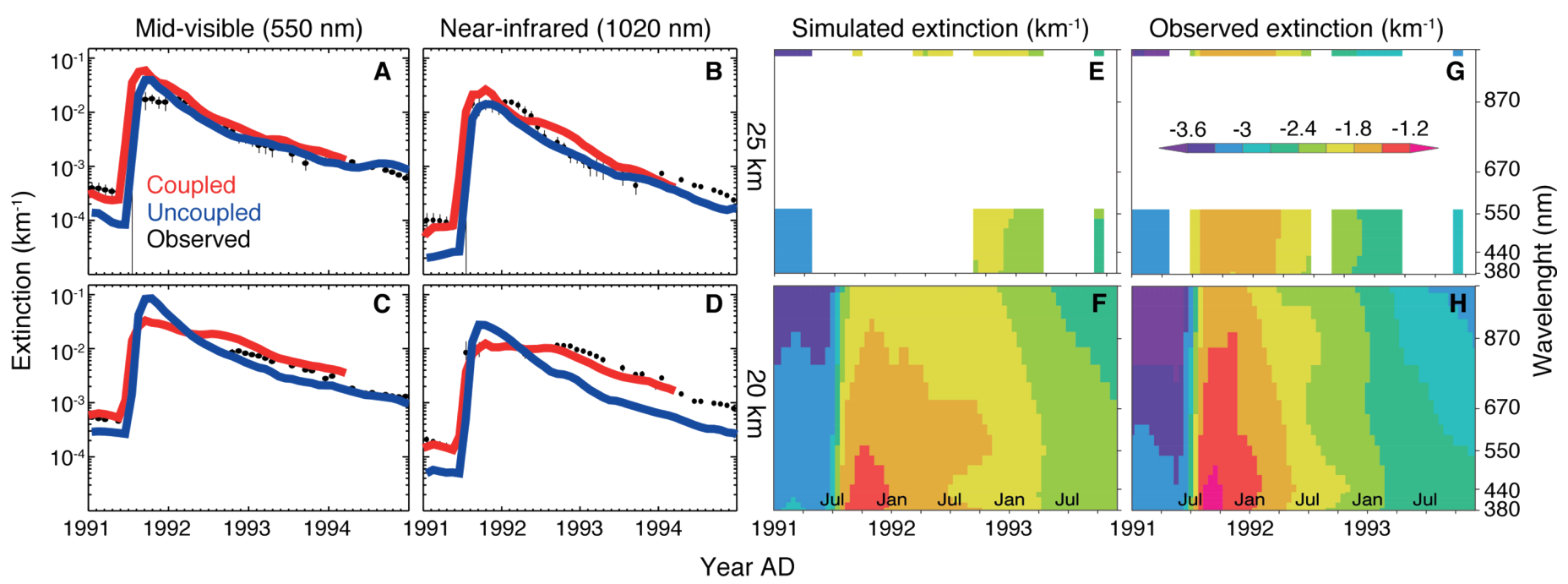

Figure 2: The SAGE-II timeseries of tropical-mean (0-15 $\mathrm{N})$ aerosol extinction in the mid-visible (550 $\mathrm{nm})$ and near-infrared (1020 $\mathrm{nm})$ at $25 \mathrm{~km}$ (A, B) and $20 \mathrm{~km}$ a.s.l. (C, D) compared to radiatively coupled (red) and uncoupled (blue) Pinatubo simulations where $10 \mathrm{Tg}$ of $\mathrm{SO}_{2}$ was injected. The evolution of the simulated extinction across the shortwave spectrum at the two altitudes is shown in panels $E$ and $F$, alongside that observed by SAGE-II v7.0 (G, H).

The CMIP5 models tend to overestimate the post-Pinatubo stratospheric warming and generally fail to capture the dynamical response and associated winter warming (Driscoll et al. 2013), which may partly be due to omission of global size variations.

\section{Climate models with interactive stratospheric aerosol}

There has been a significant advance in model capability recently with the development of a new generation of composition-climate models (CCMs) that treat the stratospheric aerosol interactively (e.g. Niemeier et al. 2009; Dhomse et al. 2014). Many of these models also include aerosol microphysical modules to calculate sedimentation rates and aerosol-radiation interactions consistently with simulated global variations in particle size distribution. Such models therefore have great potential to improve the accuracy of modeled volcanic impacts on climate and thereby increase the reliability of simulated GMST trends.

Interactive stratospheric aerosol CCMs have demonstrated capability in reproducing observed variations in particle size distribution after the Pinatubo eruption. For example, in Figure 1, the model captures the observed feature that optically active sizes (larger than $150 \mathrm{~nm}$, colored lines) were enhanced for all size channels measured by the particle counter, whereas total particle concentrations (black) were not greatly perturbed by the eruption.

Figure 2 demonstrates the potential of the models to produce new volcanic forcing datasets and illustrates how the heating of the plume strongly influences its own dispersion and subsequent radiative effects. The warming enhances upwelling in the tropics, which lofts particles to high altitudes generating a kink in the $20 \mathrm{~km}$ extinction timeseries: a minimum in early 1992 and a second maximum at the end of the year. The latter peak is likely due to particles sedimenting from the main plume, which at that time is present at higher altitudes. Combining the models and measurements may also help close a key observation gap in the post-Pinatubo SAGE-II solar occultation record. For several months following the eruption the volcanically enhanced aerosol was opaque enough to prevent measurements of aerosol extinction below $23 \mathrm{~km}$ in the tropics (e.g. Hamill et al. 2006).

A recent study of the Pinatubo eruption (Dhomse et al. 2014) showed that the satellite-observed post-eruption increase in mid-visible aerosol optical depth is consistent with a considerably lower mass of sulfuric acid in the aerosol when variations in particle size are simulated. The study also emphasized that satellite estimates of the peak global sulfur burden in the particles are around 50\% lower than the measured gas phase sulfur burden shortly after the eruption. Further analysis suggests that the coarse spatial scales used in global models may miss important loss pathways in the first days following the eruption. This could have implications on the modeling of $\mathrm{SO}_{2}$ emissions in the CCMs in order to make the simulated stratospheric aerosol properties consistent with observations.

\section{Quantifying uncertainty \\ in volcanic forcings}

These issues will be investigated in a new "Historical Eruption $\mathrm{SO}_{2}$ Emission Assessment" experiment within the model intercomparison activity of the current "SPARC Stratospheric Sulfur and Its Role in Climate" initiative (SSiRC). The activity will involve evaluating simulations of the Agung, El Chichón, and Pinatubo eruptions from a range of interactive stratospheric aerosol models and assessing how much $\mathrm{SO}_{2}$ is required to match with available observations.

Another analysis within the modeling component of SSiRC is the "Pinatubo Emulation in Multiple modelS" (PoEMS) experiment, which will quantify the uncertainty in volcanic forcings predicted by interactive aerosol CCMs. By applying novel statistical techniques (Lee et al. 2011), contributions to the overall forcing uncertainty will be attributed to a range of parameters, varied within the ensembles carried out by each participating model. In so-doing, the initiative seeks to identify to which parameter uncertainties (injection settings, chemical conversion or microphysical processes) simulated volcanic forcings are most sensitive. The SSiRC intercomparison experiments are complimentary to the VoIMIP initiative for CMIP6, which will investigate climate responses to common prescribed volcanic forcings (see Zanchettin et al., this issue).

\section{AFFILIATIONS}

${ }^{1}$ National Centre for Atmospheric Science, University of Leeds, UK

${ }^{2}$ School of Earth and Environment, University of Leeds, UK

${ }^{3}$ Department of Atmospheric Science, University of Wyoming, Laramie, USA

${ }^{4}$ Max Planck Institute for Meteorology, Hamburg, Germany

${ }^{5}$ NASA Langley Research Center, Hampton, USA

\section{CONTACT}

Graham Mann: G.W.Mann@leeds.ac.uk

\section{REFERENCES}

Canty T et al. (2013) Atmos Chem Phys 13: 3997-4031

Deshler T (2008) Atmos Res 90: 223-232

Dhomse S et al. (2014) Atmos Chem Phys 14: 11221-11246 Driscoll S et al. (2012) J Geophys Res 117, doi:10.1029/2012JD017607

Graf H-F et al. (1993) Clim Dyn 9: 81-93

Hamill P et al. (2006) In: Thomason L and Peter Th (Eds) Assessment of Stratospheric Aerosol Properties, SPARC Report No. 4: 107-176

Lacis A et al. (1992) Geophys Res Lett 19: 1607-1610 Lee L et al. (2011) Atmos Chem Phys 11: 12253-12273 Marotzke J, Forster PM (2015) Nature 517: 565-570 Niemeier U et al. (2009) Atmos Chem Phys 9: 9043-9057 Pinto J et al. (1989) J Geophys Res 94: 11163-11174 Robock A, Mao J (1992) Geophys Res Lett 19: 2405-2408 Robock A et al. (2000) Rev Geophys 38: 191-219 Sato M et al. (1993) J Geophys Res 98: 22987-22994 Timmreck C et al. (2012) WIREs Clim Change 3: 545-564 